\title{
SENTIDO DE AUSENCIAS
}

\author{
POR \\ SYLVIA MOLLOY \\ si yo me atrevo \\ a mirar y a decir \\ es por su sombra \\ unida tan suave \\ a mi nombre
}

(Ale)ANdRa PIZARniK, «Sentido de su ausencia»)

A menudo, en entrevistas, se le pregunta a la escritora hispanoamericana qué escritores la han marcado. La pregunta, de por sí difícil, se complica con el invariable añadido: qué escritoras la han marcado. Intentar aclarar la dificultad de esta doble pregunta, a partir del desasosiego con que reacciono a ella, es el propósito de estas páginas.

Se trata, en apariencia, de un pedido inocente que busca recoger un dato más. En realidad, es, de las muchas preguntas del entrevistador, la más indiscreta. Pedir nombres de precursores (no distingo, por el momento, entre los sexos) es acudir a la intimidad de quien escribe, es reclamar acceso a lo que constituye su archivo vital. Decir quién ha marcado mi escritura es decir quién soy cuando escribo. $\mathrm{Y}$ aun cuando no escribo: quienes me han marcado tiñen mi visión del mundo, me ayudan a recortar la realidad de que soy parte.

La tentación de contestar a la pregunta desviando su carga inquisitorial es fuerte: recurrir a las álgebras y los fuegos de la enumeración caótica -Flaubert y Sor Juana- o bien a la elegante y resignada aseveración de que todos los signos de mi cultura - aun los que no he leído directamente- pesan anónimamente sobre mí. No estoy marcada por tal o cual escritor, sino por la manera de leer (que es la manera de escribir) de mi época. Las dos respuestas - y menos la segunda, avara de nombres, que la primera - satisfacen medianamente al entrevistador. No satisfacen, en cambio, a quien las da y se queda pensando en las repercusiones de la pregunta inicial. ¿Cómo determinar quién me ha marcado? ¿Qué me mărca: el libro que leo o quien lo escribió? ¿Dónde rastrear esas marcas: en mi escritura (abiertamente o en negativo) o en la persona que soy o creo ser? ¿Gustar de un libro con pasión es haber sido marcada por él? ¿Cuándo, en qué momento de mi vida empieza este trabajo de marcas, de 
presiones que irán moldeando lo que escribo? ¿Las influencias son previas a la escritura? A medida que se acumulan las preguntas, la lista ideal a la que aspiraba el entrevistador, los nombres clave que le permitirían situarme, se esfuman en favor de una indagación personal de otro orden.

En un sentido la presión textual comienza desde el momento en que tomo un libro por primera vez, desde mi primera lectura. En ese caso, justo sería decir que el primer libro que me marcó fue una antología de cuentos de hadas inglesas (de una colección que practicaba un concepto nacionalista de lo feérico), con la que ejercitaba laboriosamente mi flamante competencia de lectora bajo la mirada tutelar de una tía. (Mi tía puntuaba mi lectura con comentarios de desaprobación ante ciertas violencias: los ingleses no sabían lo que eran las hadas.) A mí esos cuentos me dieron dos cosas que en su momento sólo intuí confusamente: la revelación de que el mundo de la lectura ofrecía posibilidades infinitamente más variadas que el mundo real y la certidumbre de que cuando leía era feliz. Cada escritor recuerda en sus propios términos esa primera pasión, ese comienzo de la voracidad que desemboca, años más tarde, en esa otra lectura dinámica que es la escritura.

Hay libros que se leen con fervor y que no dejan rastros en lo que escribimos; otros, que se leen de contramano, en un primer momento, y que luego -nos damos cuenta tiempo después - nos marcan, nos han marcado. Yo recuerdo haber leído a Gabriel Miró cuando era adolescente; me veo sentada una tarde en la playa al caer el sol, deslumbrada por un texto - el Libro de Sigüenza-, que más tarde me parecerá artificioso, de un amaneramiento en el que no me reconozco. Recuerdo el momento gozoso de la lectura, pero el texto se me ha vaciado sin dejar (creo) huellas perdurables ni en mi vida ni en lo que escribo. Lo recuerdo con nostalgia: me hubiera gustado que me siguiera gustando Miró. En cambio, Las ratas, de José Bianco, leído a desgana por imperioso consejo de un amigo que se proponía llenar mis lagunas, no me impresionó al principio. Lo viví como un texto confuso, desafiante, que me estaba vedado y sólo con el tiempo fue entrando en mí. Ahora sí es un texto que reconozco (en el que me reconozco) y llevo conmigo. Le debo, además del gusto por la trama perversa, la magia secreta de la palabra tumbergias.

Creo que los rastros que dejan en nosotros los libros y sus autores son tan diversos como arbitrarios. Un detalle, a veces, pesa más que toda una obra. El descarnado patetismo de una escena de Flaubert, al final de La educación sentimental -el pelo blando de Madame Arnoux- ha marcado lo que escribo más que todo Gide, a quien exalté, en un momento, como maestro. Como esos «pormenores lacónicos de larga proyección» de que habla Borges, esos detalles obran como fermento, trabajan mi texto 
en direcciones imprevistas. Cuando necesito apoyo incluso los busco, deliberadamente, a modo de talismanes: me permiten anclarme en otros textos, encontrar un respaldo cuando siento que lo que escribo es particularmente tentativo, inerme.

Hay dos maneras de establecer antepasados. Una de ellas poco tiene que ver con nuestra voluntad. Cada texto que escribimos dicta, entre líneas, sus propios precursores, refleja para el lector los meandros de nuestras lecturas previas. Quizá tengamos conciencia de esos precursores, quizá no; quizá lo que hemos escrito despierte en un lector ecos de un nombre que quiera atribuirnos. Así alguien una vez me propuso como precursor a Felisberto Hernández. Yo no lo sospechaba; tampoco lo veía como hecho del todo evidente. Sin embargo, como he leído mucho a Felisberto, he escrito sobre Felisberto y es uno de los escritores que más quiero, me dejé convencer. Los dos compartimos después de todo la «lujuria de ver».

La otra manera de establecer precursores es elegirlos. Así como Sarmiento, en Recuerdos de provincia, se elige - $\mathrm{y}$ fantasea- un linaje, el escritor o la escritora se eligen, con frecuencia, sus precursores. La comparación con la familia no es casual. En la familia que, por fatalidad inapelable es nuestra, solemos elegir a los parientes que preferimos, distinguiéndolos por sobre el igualador determinismo biológico; del mismo modo, de nuestro pasado abarrotado de lecturas, privilegiamos a unas sobre otras. Esa elección no se funda necesariamente en un criterio cuantitativo: los textos que más hemos leído o que creemos nos han marcado más. La elección puede ser arbitraria, afectada por nuestro humor, por la idea que tenemos (o queremos dar) de nosotros el día que nos hacen la pregunta, $\mathrm{y}$ hasta por el grado de sorpresa que la pregunta puede provocar en nosotros. Alguna vez - la primera - esa pregunta nos tomó desprevenidos; entonces echamos mano de algunos nombres, como quien, amenazado por el fuego, escapa de su casa con algunos pocos objetos queridos, que salva al azar de las llamas y que lo ayudarán a seguir viviendo. Esos nombres que se nos escapan de la boca, quizá con escasa reflexión, son nuestro mínimo, incómodo canon; poco a poco, como Gertrude Stein con el extraño retrato que de ella pintó Picasso, nos iremos acostumbrando a él y lo haremos nuestro. Yo dije alguna vez, sin pensarlo, que Silvina Ocampo me había marcado. Ahora sé que es así.

$A$ veces en esa lista se insinúan nombres de autores que apenas hemos leído, pero que quisiéramos que nos hubieran marcado. Así como los niños y los enfermos, en los delirios de linaje, se figuran ser hijos de emperadores o reinas, así puedo yo no sólo elegir al precursor, sino inventármelo, y el hecho mismo de inventarlo valdrá por sí mismo. No dirá nece- 
sariamente cómo es lo que escribo, pero sí cómo me pienso (o cómo me gustaría pensarme) cuando escribo: esa proyección literaria es tan reveladora como su resultado mismo. A mí me hubiera gustado que X. Z. (el nombre cambia según los días, según mi humor, según mis lecturas) me marcara; tomar ese deseo por realidad, incorporar tácitamente el mundo que asocio de modo más o menos vago con $\mathrm{X}$. $\mathrm{Z}$. (a quien acaso no he leído) dentro de mi percepción en el momento en que escribo es hacer que, de alguna manera, X. Z. me marque.

Deliberadamente he evitado distinguir hasta el final entre precursores y precursoras. No ha sido (creo) por evitar el deslinde, sino porque pienso que es necesario verlo en su especificidad. En realidad, preguntar «¿Qué escritores la han marcado?»y, acto seguido, «¿Qué escritoras?» no es una doble pregunta o una misma pregunta en dos tiempos, sino dos preguntas distintas. Si bien son pertinentes a la segunda las mismas incógnitas que mencioné para la primera — cómo determinar quiénes son esas escritoras, cuándo empezaron a marcarme, qué forma tomó su influencia, etc.-, a esos interrogantes se añaden otros. Sobre todo uno que debe encararse primero: ¿he sido marcada, y acepto ser marcada, por textos de mujeres?

En mi caso personal, si intento elegir a mis precursoras, privilegiar a aquellas en las cuales me reconozco, me encuentro ante un hecho notable: he leído a pocas mujeres. Recuerdo un hecho de mi adolescencia, tanto más nítido cuanto que fue un gesto aislado. En mi último año de colegio inglés salí primera en el examen final y gané un premio importante. E1 examen había sido administrado por la Universidad de Cambridge, que también adjudicaba el premio; se me daba, eso sí, la libertad de elegirlo. Pensé en Katherine Mansfield, de quien acababa de leer, transportada, «En la bahía». Mi compañera de banco, pedante, sugirió Chaucer. Me empeciné. Tuve que entrevistarme, muy solemnemente, con una de las autoridades del Concejo Británico (una mujer) para ser felicitada y anunciarle mi decisión. Dije de nuevo: Katherine Mansfield. El nombre no cayó bien. Se me hizo notar que habitualmente se elegía a un autor más importante, a un «clásico», pero que desde luego la decisión era mía. Seguí diciendo (sintiendo que me condenaba a lo transitorio y lo marginal en los ojos de esta mujer, acaso también en los míos) Katherine Mansfield. Me gustaría pensar que este gesto de mis dieciséis años resultó emblemático, que marcó el comienzo de una serie de elecciones semejantes, pero no fue así. Durante años leería a más hombres que a mujeres, no por decisión propia, sino porque el canon patriarcal resultaba de más fácil acceso. Todo lo favorecía: los programas universitarios, la opinión pública y un medio familiar poco dispuesto a la apertura. Nunca vi a mi padre 
leer a Jane Austen, a George Eliot, a Virginia Woolf; sí a Kipling, a Conrad, a Stevenson. Mi madre, que leía poco, opinaba que las mujeres escritoras (había conocido superficialmente a algunas: Norah Lange, Alfonsina Storni) eran todas unas extravagantes. De esa época - hablo de mis dieciocho o veinte años - recuerdo haber leído con fervor a otras dos mujeres: Colette y Carson McCullers. De Colette leí todo, maravillada. No sé si la elegiría hoy como precursora como sí sé que elegiría (que seguiría eligiendo) a Katherine Mansfield. Más que su tan mentada sensualidad, recuerdo en Colette la ironía, el humor y el placer de rozar lo prohibido. Carson McCullers confirmó sobre todo mi atracción por la marginalidad. No creo casual que, de las dos, los libros que más me tocaron fueron Claudine, de Colette, y El corazón es un cazador solitario y El miembro de la boda, de McCullers, es decir, los que tenían por protagonista a una adolescente distinta de las demás: yo misma estaba saliendo de esos parajes turbios en los que me había ayudado algo, pero no del todo, Gide.

No intento hacer aquí un resumen de mis lecturas de mujeres como quien hace un balance espiritual o un mea culpa. Sólo señalar mi azoramiento ante lo inexplicable: ¿por qué no se me habrá ocurrido leer a más mujeres? Cuando las descubría - porque hubo otras- eran como pequeñas epifanías, pero sin reverberaciones. La presión del medio ambiente no me impidió la transgresión en otros órdenes; no así en la lectura, donde practiqué un hedonismo convencional. Podrá argüirse que hay menos textos de mujeres que de hombres; eso no explica del todo mi advenimiento tardío a ellos, sobre todo si se piensa que esas pequeñas epifanías, fuertes en su momento, hubieran podido atraer hacia mí otros textos de mujeres, hacer que me abriera a ellos. Virginia Woolf, Silvia Ocampo, Delmira Agustini, Gabriela Mistral son escritoras cuyos textos hubiera podido leer antes, pero no supe encontrarlos. De alguna manera leía sin conectar.

Como toda escritura, la mía se ha ido elaborando al margen, o más precisamente en los márgenes de otras escrituras como notas, citas o comentarios apócrifos. Si entre esas escrituras no figuran notablemente las de mujeres, queda para mí la tarea de descubrirlas post facto, de establecer lazos ignorados, de ligarme a una línea de voces que no por salteadas o marginadas no existen. Inventarme, sí, precursoras: las que hubiera querido que me marcaran y no escuché con atención; fabularme un linaja, descubrirme hermanas. Hacer que aquellas lecturas aisladas se organicen, irradien y toquen mi texto.

La tarea es doblemente importante, creo, en un contexto hispanoamericano. En nuestros países, la literatura femenina, hasta hace poco, gozaba 
de una recepción dudosa, sobre todo si la escribían mujeres hispanoamericanas; en la Argentina se conocía a Marguerite Duras cuando no se conocía a Elena Garro. Cuando Gabriela Mistral le reprocha a Victoria Ocampo el haber ignorado a Alfonsina Storni, Ocampo contesta con toda naturalidad -esto en 1945- que nunca tuvo la ocasión de establecer contacto con ella: no se le ocurría que fuera indispensable. Si hoy día sorprende la ceguera de tal declaración es porque la necesidad del contacto se ha vuelto evidente. Es hora -o por lo menos lo es para míde reconocerme en una tradición que, sin que yo lo supiera del todo, me ha estado respaldando. No sólo eso; es hora de contribuir a convocarla en cada letra que escribo. 